\title{
Correction to: A systematic review of stakeholder views of selection methods for medical schools admission
}

\author{
M. E. Kelly ${ }^{1 *}$, F. Patterson ${ }^{3}$, S. O'Flynn², J. Mulligan ${ }^{1}$ and A. W. Murphy ${ }^{1}$
}

\section{Correction}

Following publication of the original article [1], the author report typographical errors in the

Figure 1 Study Search Strategy and Review Process - the lowest box on the right hand side should read "Full-texts excluded with reasons $(\mathrm{n}=37)$ " instead of " $(\mathrm{n}=38)$ "

Page 3 of the text, column 2, paragraph 2, second-last sentence should be "Subsequently 71 records were included for full review and 37 excluded" instead of "Subsequently 70 records were included for full review and 38 excluded"

\section{Author details}

${ }^{1}$ Discipline of General Practice, Clinical Science Institute, National University

of Ireland, Galway, Ireland. ${ }^{2}$ University College Cork, Cork, Ireland. ${ }^{3}$ Work

Psychology Group, Derby, UK.

Received: 28 June 2018 Accepted: 2 July 2018

Published online: 05 July 2018

\section{Reference}

1. Kelly ME, et al. A systematic review of stakeholder views of selection

methods for medical schools admission. BMC Medical Education. 2018;18:

139. https://doi.org/10.1186/s12909-018-1235-x.

\footnotetext{
* Correspondence: maureen.kelly@nuigalway.ie

'Discipline of General Practice, Clinical Science Institute, National University

of Ireland, Galway, Ireland
} 